\title{
RAMAN SPECTROSCOPY OF OOLITIC HEMATITE: EVIDENCE OF BIOSIGNATURES IN IRON OXIDE RICH ROCKS
}

\section{Allison Dowling ${ }^{1}$, Carson Rufledt 1 , Scott Brande ${ }^{2}$, Craig Marshall ${ }^{1,3}$}

'Department of Geology, University of Kansas, Lawrence KS, 66045, ${ }^{2}$ Department of Chemistry, University of Alabama, Birmingham AL, 35294, ${ }^{3}$ Department of Chemistry, University of Kansas, Lawrence KS, 66045

\section{Objective}

Despite the extensive distribution of oolitic hematite, the origin and conditions of their formation is still under considerable debate. Currently, it is postulated that these enigmatic deposits are mineralogically composed of hematite, chamosite, or iron oxyhydroxides. Likewise, little is known about the temperature of the fluids, and whether biological or non-biological processes occurred to induce the precipitation and hence formation of these extensive deposits. Therefore, in order systematic approach to elucidate the mineralogy and chemistry of oolitic hema samples located in the USA.

\section{Materials and Methods}

Samples

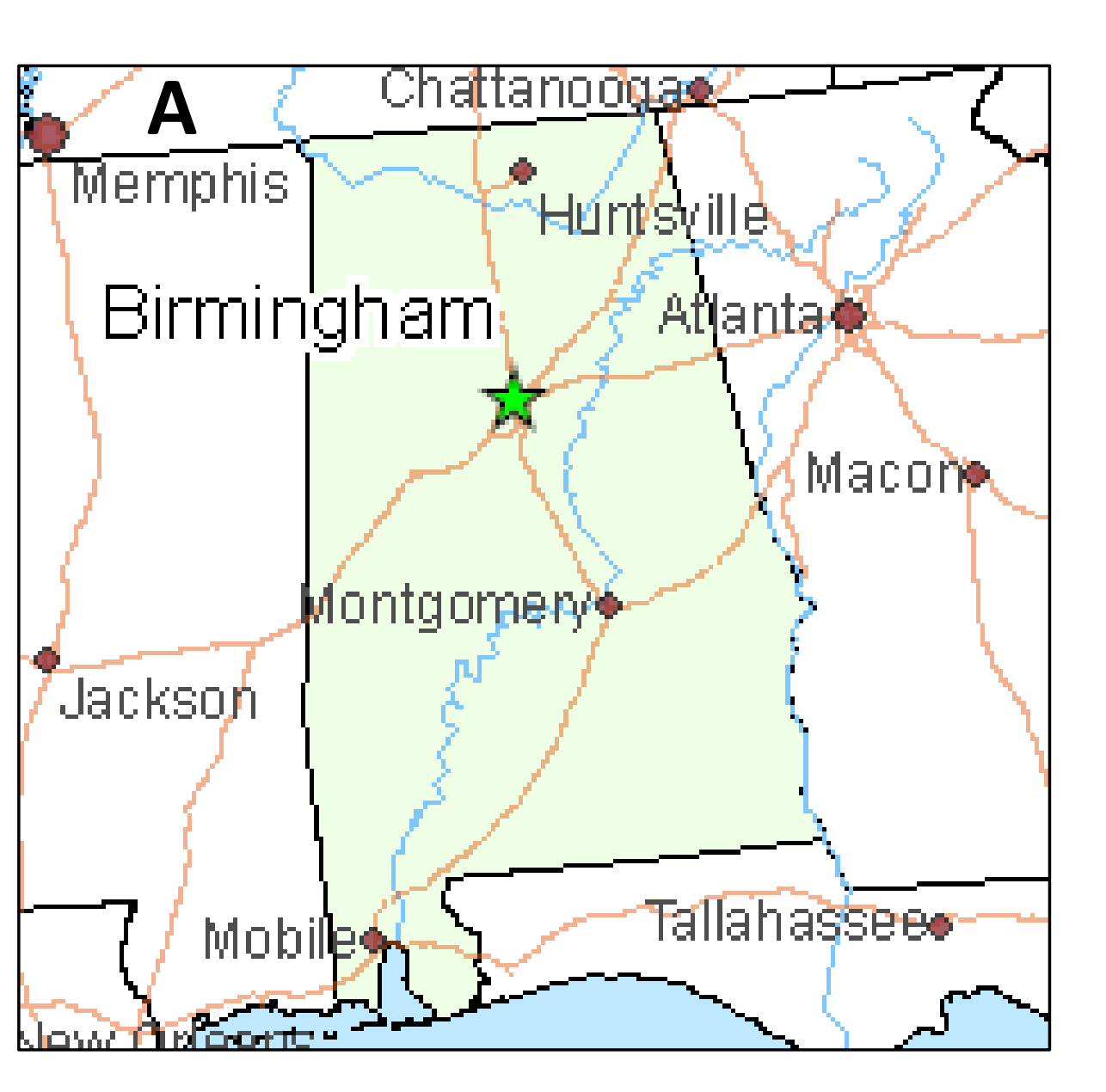

Figure 1: A) Locality of oolitic hematite and B) Geological map'

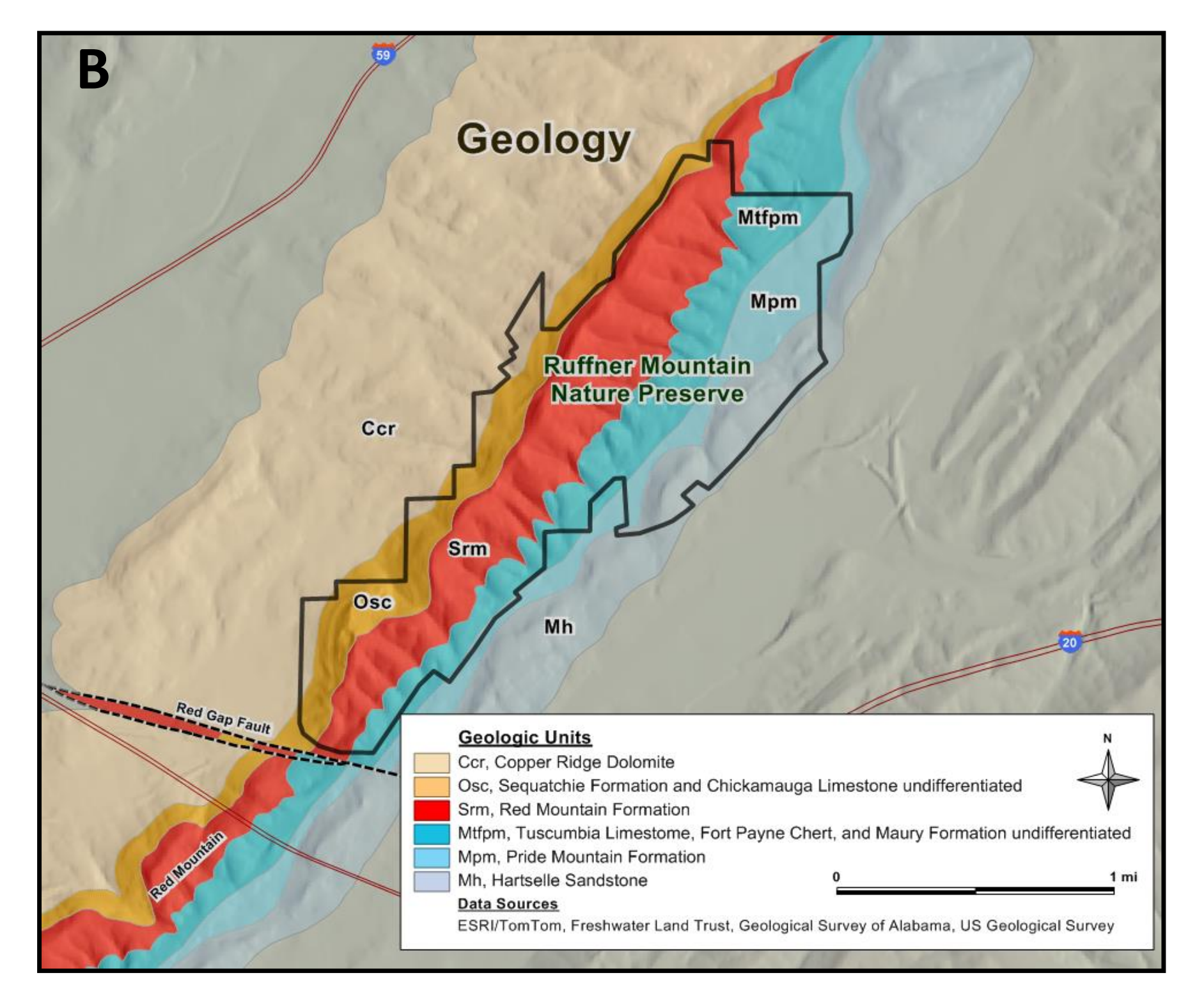

The Lower Silurian Red Mountain Formation consists of fossiliferous material, fine to medium grained sandstone interbedded with shale and lesser siltstone, oolitic ironstone, pebbly sandstone, and fossiliferous limestone ${ }^{1,2}$ (figure 1). During the shallow tidal delta ${ }^{2}$.

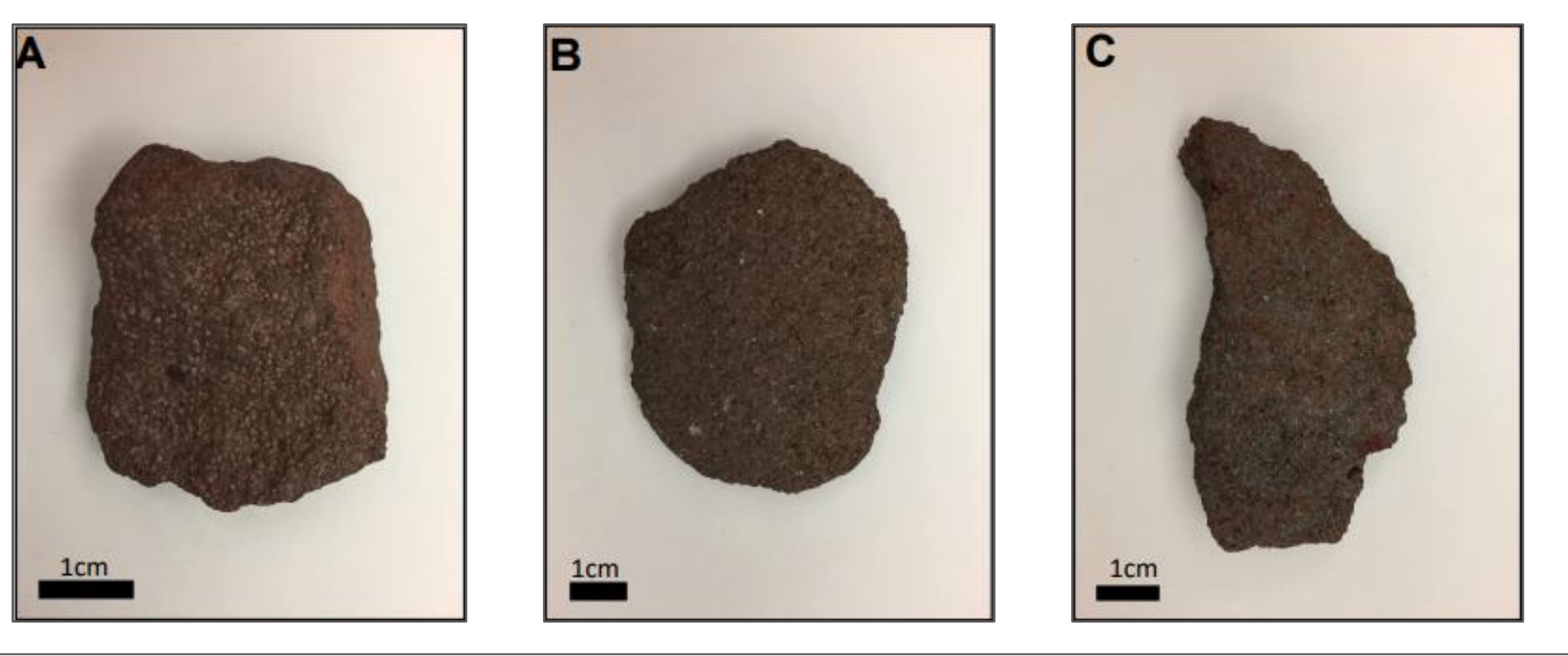

Figure 2: Oolitic hematite hand samples. A) Lower Silurian Red Mountain Formation, where samples $\mathrm{B}$ ) and $\mathrm{C}$ ) were obtained from the mineralogy teaching collection.

\section{Raman spectroscopy}

Backscattered Raman spectra were collected at room temperature with a Renishaw in Via Reflex Raman Microprobe. The Raman scattered light was dispersed by a diffraction grating with 2400 grooves $/ \mathrm{mm}$, and the signal was analyzed with a Peltier-cooled CCD camera $(1024 \times 256$ pixels). Spectra were collected over the Raman shift region $100-1800 \mathrm{~cm}^{-1}$ with spectral resolution of ca. $2 \mathrm{~cm}^{-1}$. Sample excitation was achieved with an argon ion laser emitting at a wavelength of $514.5 \mathrm{~nm}$. The laser was focused onto a $1.6 \mu \mathrm{m}$ spot size thro
$20 \mathrm{X}(\mathrm{NA}=0.40)$ microscope objective. The attached microscope is a Leica DMLM. Spectra were summed over five 30 s accumulations.

\section{Results and Discussion}

Raman spectroscopy reveals the presence of hematite, quartz, apatite, rhodochrosite, siderite, magnesite, low Mg calcite, and calcite (table 1).

\begin{tabular}{l|c} 
Mineral Identified & Diagnostic phonon modes $\left(\mathrm{cm}^{-1}\right)$
\end{tabular}

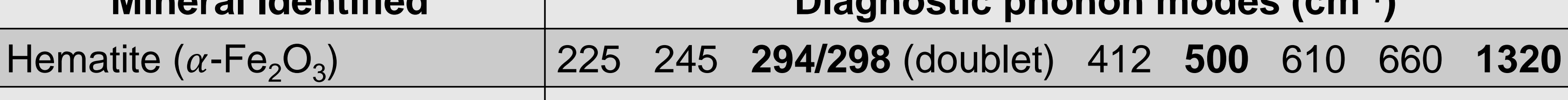

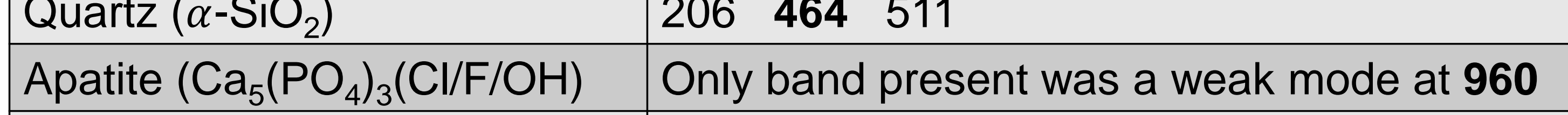

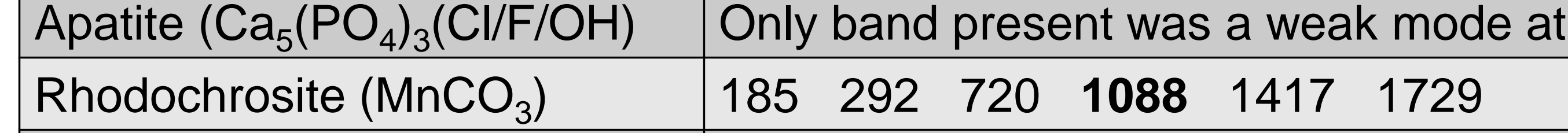
\begin{tabular}{l|llllll}
\hline Rhodochrosite $\left(\mathrm{MnCO}_{3}\right)$ & 185 & 292 & 720 & $\mathbf{1 0 8 8}$ & 1417 & 1729 \\
\hline Siderite $\left(\mathrm{FeCO}_{3}\right)$ & 184 & 287 & $\mathbf{7 3 5}$ & $\mathbf{1 0 8 7}$ & 1728
\end{tabular} \begin{tabular}{|l|lllllll} 
Siderite $\left(\mathrm{FeCO}_{3}\right)$ & 184 & 287 & 735 & 1087 & 1728 & \\
\hline Magnesite $\left(\mathrm{MgCO}_{3}\right)$ & 215 & 333 & 738 & 1094 & 1445 & 1762 \\
\hline
\end{tabular} \begin{tabular}{llllllll} 
Magnesite $\left(\mathrm{MgCO}_{3}\right)$ & 215 & 333 & 738 & $\mathbf{1 0 9 4}$ & 1445 & 1762 \\
\hline Calcite $\left(\mathrm{CaCO}_{3}\right)$ & 154 & 280 & $\mathbf{7 1 1}$ & $\mathbf{1 0 8 5}$ & 1434 & 1747
\end{tabular} \begin{tabular}{|l|lllllll|} 
Calcite $\left(\mathrm{CaCO}_{3}\right)$ & 154 & 280 & 711 & 1085 & 1434 & 1747 \\
\hline Low Mg calcite $\left(\mathrm{CaMg}\left(\mathrm{CO}_{3}\right)\right)$ & 154 & 280 & 711 & $\mathbf{1 0 8 8}$ & 1434 & 1747 \\
\hline
\end{tabular}

Table 1: Diagnostic phonon modes. Relative wavenumbers obtained from representative Raman spectra of each mineral present within the oolitic hematite. These spectra where identified by comparison with the literature e $^{3.5}$. The bold relative
wavenumbers represent the most intense diagnostic phonon mode for identification.

Moreover, the hematite composing this formation varies from very poor crystallinity, and poor to moderate crystallinity, which is demonstrated by the Raman spectroscopic analysis (igure 3). The single-crystal hematite shows all the 7 group theoretically predicted phonon modes and the 2 LO line. While the moderate crystallinity hematite shows reduced intensity and line-broadening. And This is the poor crysallinily heman modes. This is expected for poor crystallinity hematite ${ }^{3}$.

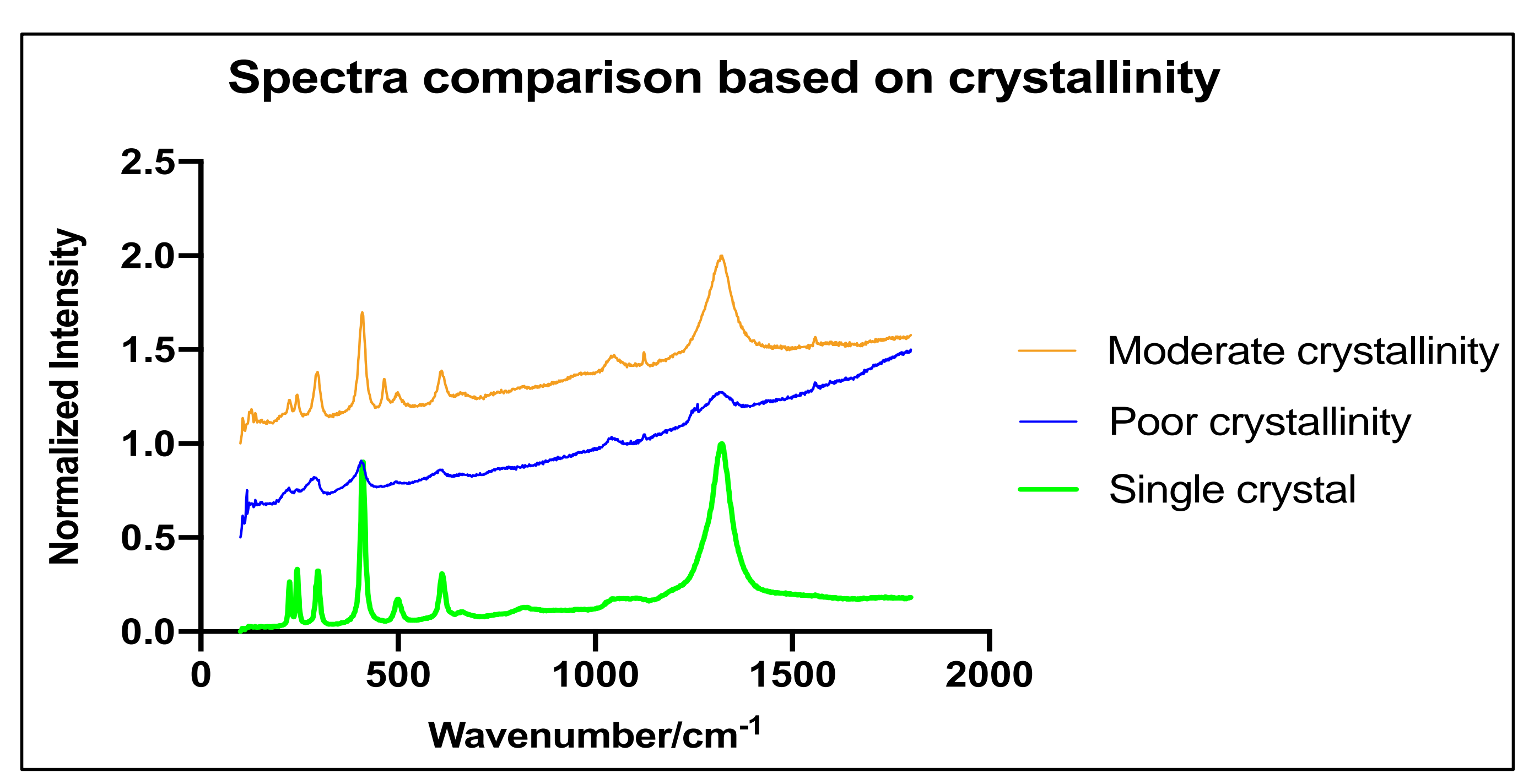

Figure 3: Stack plot of single-crystal (purchased Wards Scientific), oolitic hematite of poor-crystallinity, and poor- to moderate-crystallinity.

Interestingly, the Raman spectroscopic analyses showed the presence of $s p^{2}$ carbonaceous materials, associated with the larger size ooids and with dark brown coloring (figures 4 and 5 ).

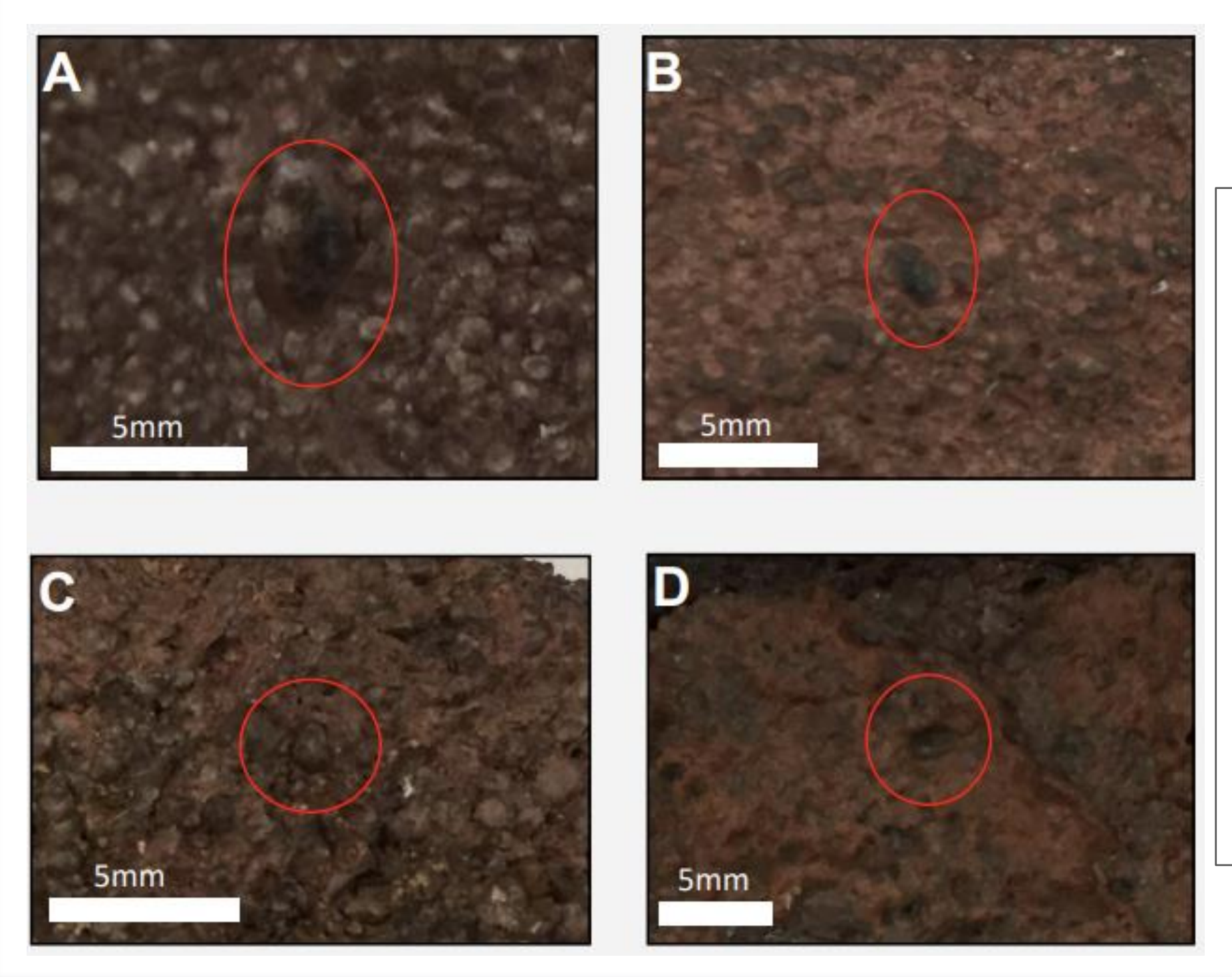

Figure 4: Different ooids located on various oolitic samples where higher concentrations of $s p^{2}$ carbonaceous
materials are found. (A and B) Ooid of materials are found. (A and B) Ooid of
interest located on Red Mountain formation sample seen in figure 2A. (C) Ooid of interest located on sample seen in Oigure 2B. (D) Ooid of interest located on sample seen in figure $2 \mathrm{C}$.

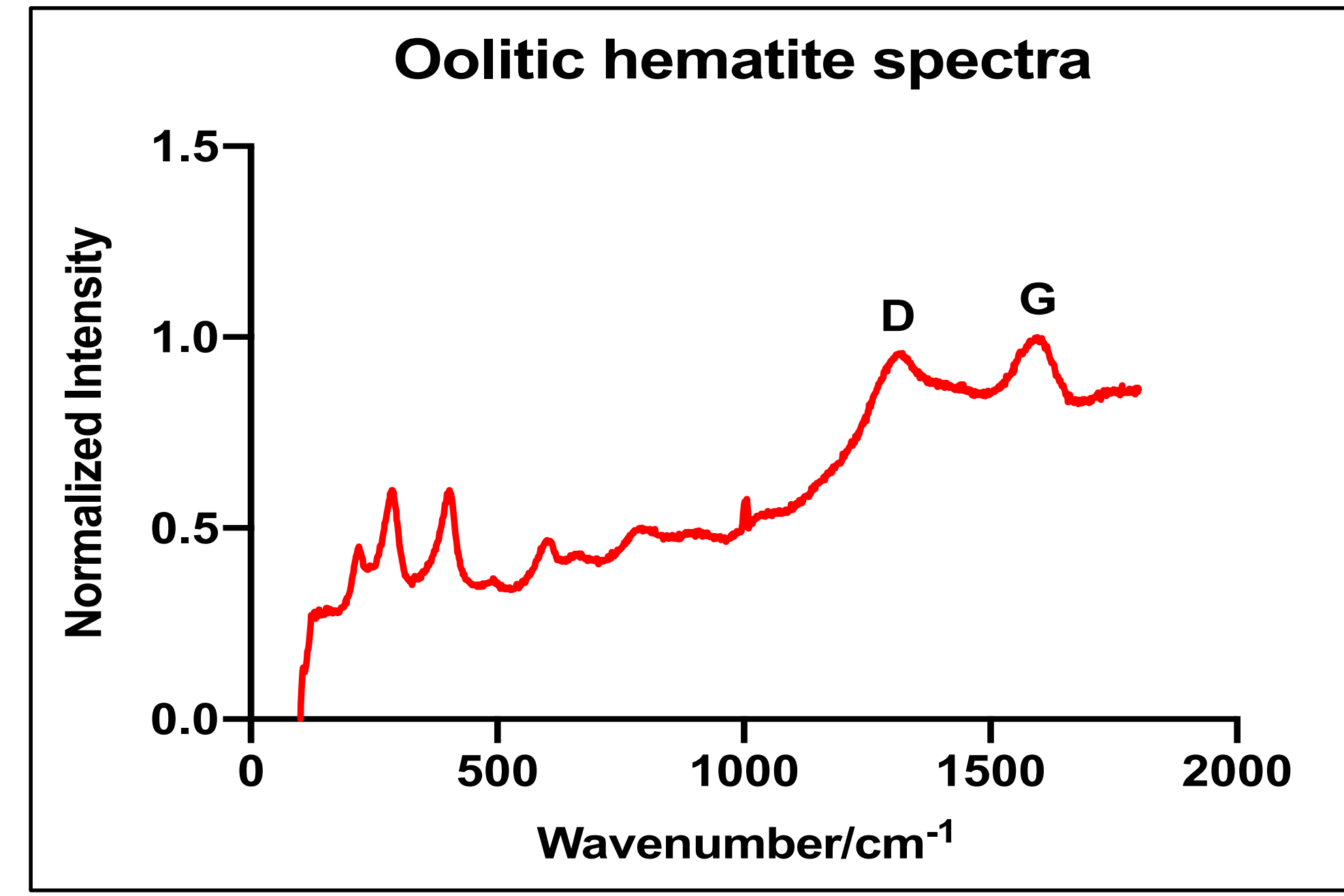

Figure 5: Representative spectrum indicating the presence of kerogen. The $G$ and $D$ bands at ca. 1600 and $1350 \mathrm{~cm}^{-1}$, respectively, are indicative of $s p^{2}$ carbonaceous hematite.

Comparison with the literature ${ }^{6}$ reveals that the representative spectra acquired on the $s p^{2}$ carbonaceous materials from various samples of oollic hematite are epresentalve or heorganic material undergoing a the mal malure palhway indicative of 60-140 C which, is consistent with themally immature diagenetic alteration. This would indicate the preserved remains of biology (i.e. kerogen) and that the fluids of formation of this deposit never exceeded $140^{\circ} \mathrm{C}$.

Further evidence to the role of biogenicity in the formation of this deposit is the presence of rhodochrosite. The deposition of rhodochrosite is generally an

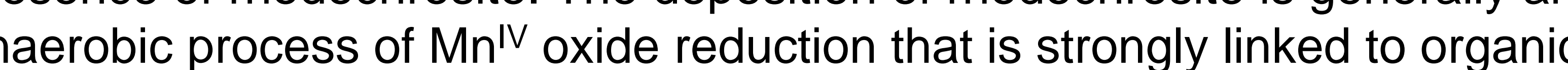
degradation in sedimentary systems by microbes?

\section{Conclusions and Implications}

For the first time, we demonstrate that the mineralogy of these enigmatic deposit is not as simple as previously supposed, but instead consist of a variety of mineralogy, including: hematite, quartz, apatite, rhodochrosite, siderite, magnesile, low Mg calcite, and calcite. Also, we demonstrate that the hematte Lastly, taken together, the presence of low temperature kerogen and rhodochrosite are strongly indicative of a biological origin of these deposits.

Future work will concentrate on obtaining a thin section to further document the localization of kerogen with respect to ooid morphology.

\section{Acknowledgements and References}

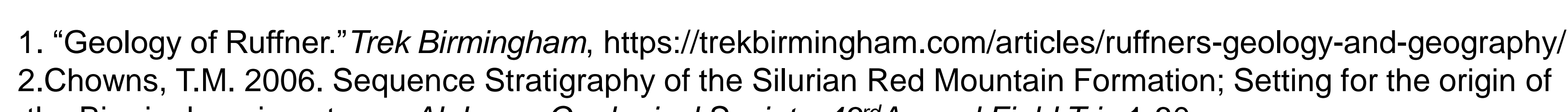
the Birmingham ironstones. Alabama Geological Sociely, 43 Hannual Field Trip, 1-30 the Raman scattering of hematite. (2019) J. Raman Spectrosc. (in press)
4. Marshall, C. P., Emry, J., \& Olcott Marshall, A. (2011). Haematite pseudomicrofossils present in the 3.5 billion year old Apex Chert. Nature Geoscience, 4, 240-243. Raman spectroscopy of the eight natural carbonate 6. Marshall, C. P., Edwards, H. G. M., \& Jehlicka, J. (2010). Understanding the application of Raman

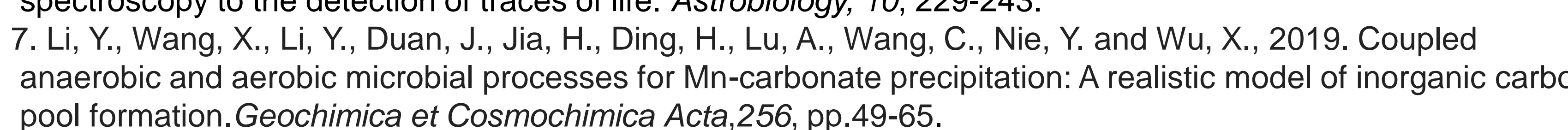

